\title{
Optical Performance of Tin Doped Indium Oxide (ITO) Thin Films Prepared By Sol Gel Dip Coating Techniques Using Acrylamide Route
}

Ramanathan Govindarajan ( $\sim$ gramsriram@gmail.com )

Sriram Engineering College https://orcid.org/0000-0001-5388-9032

Murali K.R

University of Madras

\section{Research Article}

Keywords: ITO, sol gel, Transmission spectra, optical behaviour

Posted Date: April 22nd, 2021

DOl: https://doi.org/10.21203/rs.3.rs-409058/v1

License: (c) (1) This work is licensed under a Creative Commons Attribution 4.0 International License.

Read Full License 


\section{Optical performance of Tin doped Indium Oxide (ITO) thin films prepared by sol gel dip coating techniques using Acrylamide route}

\section{G. Ramanathan ${ }^{1}$, K.R.Murali ${ }^{2}$}

${ }^{1}$ Department of Physics, Sri Sairam Engineering College, Chennai, 600044 India

${ }^{2}$ Department of Theoretical Physics, University of Madras, Chennai, India.

\section{Abstract:}

At present various oxide of metal semiconductors play significant role in the field of electronics device. Most of the semiconductor devices exploit the special characteristics of the junction between a p-type and n-type semiconductor, these devices can be made extremely small in size and they are incredibly fast in their response. Generally metal have good reflectivity in the electromagnetic region of infrared and visible radiation. Indium oxide material doped with tin (ITO) are recently used in the substrate material for various applications, because of it has special properties are low resistivity and high optical transmittance in the visible region. In this paper, we prepare ITO films with different tin concentration $(5 \%, 10 \%, 30 \%, 50 \%$ and $70 \%)$ using acrylamide sol gel dip coated method and its results were reported. TCO materials have good electrical conductivity and optical transparency, and also it has n-type semiconductor with a band gap between 3.5 and $4.3 \mathrm{eV}$. An X-ray study indicates all the prepared samples were bixbyte structure. Optical behaviour of materials can be understood in the near infrared and visible spectrum. Some optical parameters refractive index, extinction coefficient and dielectric constant of ITO films are calculated from the data received from the UV transmission studies. Using W-D model the dispersion of refractive index was calculated. The optical band gap, oscillator energy, dispersion energy and optical conductivity and $\mathrm{N} / \mathrm{m} *$ ratio were estimated and this material is well suitable for dye sensitized solar cell and sensor application.

Keywords: ITO, sol gel, Transmission spectra, optical behaviour Corresponding Author: G.Ramanathan Email: gramsriram@gmail.com 


\section{Introduction:}

Indium oxide doped with tin (ITO) is likely to be very good materials in the field of material science research group, in the room temperature, the material has wide band gap of $3.5-4.3 \mathrm{eV}$. Now-a-days ITO films used in the field of optoelectronics such as varistors, gas sensor, biosensors, transparent electrode, solar energy efficient windows, P-N junction emitting light, panel display etc. The film thickness and substrate temperature are major role to maintain the optimum condition in visible region (transparency) and near IR regions (reflectance), and also percentage of dopant, annealing temperature are optimized. Today several techniques was used to prepare ITO films including the sol gel process [1] chemical evaporation [2] pulsed laser deposition [3] and electron beam evaporation [4]. All the methods are very expensive and require for high vacuum so that we choose sol gel dip coating method. These techniques are required minimum tool cost and inexpensive method for depositing films. We know that most of the optoelectronic materials are the function of wavelength and also to predict photo electric behaviour of a device. Therefore an accurate knowledge of the structural and optical properties of ITO is important for the designing optoelectronics device. In this paper we studied some of optical behaviour such as refractive index, extinction coefficient optical band gap and complex dielectric constant and transmittance, absorbance of ITO film deposited on glass substrate.

\section{Experimental procedure:}

Using glass substrate the binary compound (Indium oxide) doped with tin (ITO) were deposited on one of the chemical methods such as sol gel techniques. The coating sols were prepared using $10 \mathrm{ml}$ of $0.45 \mathrm{M}$ solution of Indium $\left(\mathrm{InCl}_{3} 4 \mathrm{H}_{2} \mathrm{O}\right)$ and tin salts $\left(\mathrm{SnCl}_{4} 5 \mathrm{H}_{2} \mathrm{O}\right)$ were taken in a clean glass beaker. This mixture was heated to $70{ }^{\circ} \mathrm{C}$ and we choose the $\mathrm{pH}$ in the range of 9 then by the addition of $0.25 \mathrm{gm}$ of N,N,bis methylence acrylamide, 20 minutes after we add $2 \mathrm{mg}$ ammonium persulphate initiator was mixed to the solutions. After few minutes the solutions appear viscous nature. We take glass substrate in the size of 
breadth is $2.5 \mathrm{~cm}$ and $7.5 \mathrm{~cm}$ length and removal rate of the substrate is $1 \mathrm{~cm} / \mathrm{min}$. After the film formation the film surface was dried in microwave oven for 15 min followed by the heat treatment $350^{\circ}$ to $450^{\circ}$ for different duration time is $15 \mathrm{~min}$ to $90 \mathrm{~min}$. The time duration for $50 \mathrm{~min}$ is well optimised. Using surface profilometer to measure the films thickness its vary from $450 \mathrm{~nm}$ to $950 \mathrm{~nm}$ to increase of temperature.

\section{Result and discussion:}

The XRD techniques is used to determining the atomic and molecular structure of ITO films using $\mathrm{CuK} \alpha$ radiation corresponding to $\mathrm{X}$-ray wavelength is $0.154 \mathrm{~nm}$. Fig 1 shows $\mathrm{X}$-ray diffraction pattern of ITO thin films (10\% of tin oxide) prepared at various composition formed at different temperature. From the XRD measurements all the samples exhibit cubic bixbyite structure of Indium oxide and any other characteristic peak ( $\mathrm{Sn}, \mathrm{SnO}$, and $\left.\mathrm{SnO}_{2}\right)$ are absent, which indicates that the Sn atoms are probably incorporated substitutionsly into the indium oxide lattice [5-6]. Fig 2 shows the mean crystallite size of ITO films vs different tin concentration. From the graph we measure the mean crystallite size using Debye's Scherer equation from the line broadening of the (222) reflection. At low tin concentration both the microstructure and dislocation density are minimum which indicate the concentration of lattice imperfection leading to prepared orientation as shown in table 1.[2]

Fig.3 shows the Energy dispersive X-ray microanalysis it is used for the elemental analysis various composition ITO films (10\%) in which the $\mathrm{SnO}_{2}$ content (95\% to 30\%) was determined to be 68.0 at $\%, 58$ at $\%, 47$ at $\%, 38$ at $\%, 29$ at $\%, 19$ at $\%, 14$ at $\%, 9$ at $\%, 5$ at $\%$ respectively

Fig.4 exhibits image of scanning probe micrometer of $10 \%$ tin concentration of ITO films formed at $450^{\circ} \mathrm{C}$ with $10 \%$ of tin concentration. We take all the composition of tin sample we reported $10 \%$ tin concentration, from the graph we observed that the grain size decreases with increase of tin concentration. This is supported by the XRD data. And also we found the surface roughness it values in the range of $0.20 \mathrm{~nm}$ to $1.25 \mathrm{~nm}$. 
Already we find the resistivity of the films decreased from $20 \mathrm{ohm} \mathrm{cm}\left(\operatorname{In}_{2} \mathrm{O}_{3}\right.$ films formed at $450^{\circ} \mathrm{C}$ ) to $0.01 \mathrm{ohm} \mathrm{cm}$ as the tin concentration increases to $10 \%$. Further increase of tin oxide content caused increased in resistivity. Beyond $10 \%$ tin the resistivity increases from $0.1 \mathrm{ohm} \mathrm{cm}$ to $250 \mathrm{ohm} \mathrm{cm}$.at $70 \%$ tin concentration. The mobility and carrier concentration increase with increase of tin concentration up to 10 at $\%$ beyond which, they decrease. The $\mathrm{N}_{\mathrm{d}}$ increased from $3.85 \times 10^{17} \mathrm{~cm}^{-3}\left(\operatorname{In}_{2} \mathrm{O}_{3}\right.$ films formed at $\left.450^{\circ} \mathrm{C}\right)$ to $1.25 \mathrm{x}$ $10^{20} \mathrm{~cm}^{-3}$ up to 10 at $\%$, beyond this value of $\mathrm{SnO}_{2}$ content, the carrier density decreases. The value of mobility increased from $1.35 \times 10^{-4} \mathrm{~m}^{2} \mathrm{~V}^{-1} \mathrm{~s}^{-1}$ to $49.93 \times 10^{-4} \mathrm{~m}^{2} \mathrm{~V}^{-1} \mathrm{~s}^{-1}$ up to 10 at $\%$ $\mathrm{SnO}_{2}$, beyond which the mobility decreases [7]. Fig.5 shows the variation of resistivity, mobility and carrier concentration with concentration of tin. The value of mobility and carrier concentration decreased from $49.93 \times 10^{-4} \mathrm{~m}^{2} \mathrm{~V}^{-1} \mathrm{~s}^{-1}$ to $9.32 \times 10^{-4} \mathrm{~m}^{2} \mathrm{~V}^{-1} \mathrm{~s}^{-1}$ and from $1.25 \mathrm{x}$ $10^{20} \mathrm{~cm}^{-3}$ to $2.69 \times 10^{15} \mathrm{~cm}^{-3}$ respectively as the tin concentration increased up to $70 \%$. The data are presented in table.2.

The increase in resistivity beyond $10 \%$ Sn can be explained as follows, Most of the literature[8-9] survey describes the solubility of Sn atoms in the indium oxide lattice, the maximum solubility of tin atoms is approximately 10 at. $\%$. In the case lower than $10 \%$,of tin that is $\mathrm{Sn}^{4+}$ ions substitute $\mathrm{In}^{3+}$ ions in the cation sub lattice. Due to the replacement of $\mathrm{In}^{3+}$ instead of $\mathrm{Sn}^{4+}, \mathrm{Sn}$ atoms act as n-type donors, and the resistivity decreases with the $\mathrm{Sn}$ concentration. Similarly in the case higher tin content, no more Sn-atoms can be embedded in the $\mathrm{In}_{2} \mathrm{O}_{3}$-lattice, and the resistivity increases. This increase of resistivity may be due to interstitial Sn-atoms which act as charged trapping centres for the electrons [10]. Here there is no phase separation and no Bragg reflections of $\mathrm{SnO}_{2}$ in the crystalline ITO-material does not occur in the crystalline $\mathrm{SnO}_{2}$ material were detected for films with $\mathrm{SnO}_{2}$ concentration up to $70 \%$ in XRD measurements. 
Under proper environment conditions, the optical properties of $\mathrm{Sn}$-doped $\operatorname{In}_{2} \mathrm{O}_{3}$ films at various compositions were analysed. The Oxygen defect play very important role in the prepared samples. The loss of transmission is responsible for the grain boundaries with an increase in Sn dopant content. Thus a decrease in grain size with increase Sn concentration resulted in an increase in grain boundaries in $\operatorname{In}_{2} \mathrm{O}_{3}$ films. In this sol gel techniques we have to use glass substrate prepared films behaves as transparent material in the wavelength range of 450 and $1100 \mathrm{~nm}$, because the transmittance values are high at these wavelengths. The transmittance values slightly increases so increase in highly transmitting properties of ITO. The transmittance spectrum gives the information of surface Plasmon's resonance indicating the crystallite size in the nanometre range. Transmittance spectra give the information of transmittance of ITO film deposited on glass substrate and also we found that transmittance value increases from $50 \%$ to $80 \%$. The transmittance of the films exhibited ripples pattern due to interference of light which may due to the characteristic of interference between light and nanostructured materials [11]. The transmission was found to be maximum for low $\mathrm{SnO}_{2}$ concentration of $\mathrm{In}_{2} \mathrm{O}_{3}$ and decreased with an increase in $\mathrm{SnO}_{2}$ concentration. The two factors such as oxygen vacancies and scattering at grain boundaries are important role in the decrease of optical transmission.

N-type of Sn-doped $\operatorname{In}_{2} \mathrm{O}_{3}$ materials has indirect band gaps and its optical property such as absorption well suitable for photovoltaic applications. From the optical absorption data we determined the optical absorption measurements. The value of absorption coefficient calculated from the following equation

$$
\alpha=\frac{1}{t} \operatorname{In}\left(\frac{A}{T}\right)
$$

where $\alpha$ is the absorption coefficient in $\mathrm{cm}-1$. $\mathrm{T}$ is the thickness of the films. $\mathrm{A}$ is absorbance and $\mathrm{T}$ is transmittance. The nature of transition is determined using the following equation 


$$
\alpha h \gamma=A(h \gamma-E)^{n}-
$$

where $\mathrm{h} \gamma$ is photon energy Eg is an energy gap. A is energy dependent constant and $\mathrm{n}$ is an integer. The optical band gap value measured all the composition of Sn doped Indium oxide thin films. They are obtained by extrapolating the linear portions to the energy axis as shown in fig 6 . From the graph we observed that ITO thin films exhibit indirect transition, its band gap value in between 3.85 to $4.02 \mathrm{eV}$. The band gap value increases with increase in tin concentrations in the indium oxide lattice. In the earlier report $[6,12,21]$ the allowed direct transitions of different ITO thin films and their optical band gap is 3.5 to $4.5 \mathrm{eV}$. Using the observed reading from the optical transmittance spectra to calculate the refractive index and the extinction coefficient using the following equation

$$
\begin{aligned}
& \mathrm{N}=\left[N_{1}+\left(N_{1}{ }^{2}-\mathrm{s}^{2}\right)^{1 / 2}\right]^{1 / 2} \\
& \mathrm{~N} 1=2 \mathrm{~s} \frac{\mathrm{TM}-\mathrm{Tm}}{T_{M} T_{m}}+\frac{s^{2}+1}{2}
\end{aligned}
$$

$\mathrm{T}_{\mathrm{M}}$ and $\mathrm{T}_{\mathrm{m}}$ are the values of maximum and minimum transmission values at a particular wavelength $\mathrm{s}$ is the refractive index of the substrate. Refractive index can be estimated by extrapolating envelops corresponding to $\mathrm{T}_{\mathrm{M}}$ and $\mathrm{T}_{\mathrm{m}}$. Extinction coefficient $(\mathrm{k})$ of the ITO films are estimated using the following equation

$$
\mathrm{K}=\frac{\alpha \lambda}{4 \pi}
$$

Fig.6 shows the plot of refractive index as a function of wavelength $\lambda$ for different percentages of $\mathrm{SnO}_{2}$ in ITO films. The refractive index (n) was evaluated from the measured transmittance versus wavelength graph [13]. The refractive index was found to decrease with wavelength. It was observed that the refractive indices of the Sn-doped $\operatorname{In}_{2} \mathrm{O}_{3}$ thin films were smaller than for the pure $\mathrm{In}_{2} \mathrm{O}_{3}$ film in the measured wavelength range [14]. The decrease in refractive index was attributed to the lowering in the value of grain size and increase in the porosity of the ITO film with the increase in Sn concentration 
Various compositions of tin doped indium oxide thin films and its dielectric behaviour as shown in fig.7. Using the following formula the real $\left(\epsilon_{r}\right)$ and imaginary $\left(\epsilon_{i}\right)$ parts of the dielectric constant were determined.

$$
\begin{aligned}
& \epsilon=\epsilon_{r}+\epsilon_{i}=(n+i K)^{2} \text {--------- (6) } \\
& \epsilon_{r}=n^{2}-k^{2} \text {--------------- (7) } \\
& \text { And } \epsilon_{i}=2 \mathrm{nk} \text {----------- (8) }
\end{aligned}
$$

The dielectric constant is one of the well known properties of materials. The dielectric constants (real part) provide the speed of light slowing down in the material. From the graph we observed that the higher refractive index value of the glass substrate of prepared films has maximum value of real part of the dielectric constant. Similarly the imaginary part of the dielectric constant value has minimum value because prepared films have low extinction coefficient value. The dispersion and dissipative rate of the wave in the medium is calculated by the real and imaginary part of the dielectric constant. Using the following equation the optical conductivity was studied.

$$
\sigma=\alpha \text { nc }
$$

Using W.D model, some of the optical properties such as dispersion and spectral dependence of the refractive index of many semiconductors are calculated from the following equations.

$$
n^{2}=1+\left(\frac{E_{0} E_{d}}{E_{2 o-(h \gamma) 2}}\right)
$$

Where $\mathrm{n}$ is the refractive index, $\mathrm{E}_{\mathrm{o}}$ is the average excitation energy known as the oscillator energy. $E_{d}$ is the dispersion energy called the oscillator strength and $h \gamma$ is the incident photon energy. The detailed procedure of dispersion parameter such as average excitation energy and dispersion energy were estimated [15]. When a graph is plotted between $\left(n^{2}-1\right)^{-1}$ versus $(h \gamma)^{2}$ for ITO thin films, which yields a straight line for normal behaviour having the slope $\left(E_{0} E_{d}\right)^{-1}$ and the intercept with the vertical axis equal to $E_{0} / E_{d}$. The values of the parameter $E_{0}$ and $E_{d}$ 
can be estimated from the positive curvature deviation from linearity at longer wavelength is usually observed due to the negative contribution of lattice vibrations on the refractive index. The value of optical constant reported in the table. Then carrier concentration has been calculated from the plasma frequency whose expression is given below

$$
\epsilon=\epsilon_{\alpha}-\left(\epsilon_{\alpha} w_{p} 2\right) / w^{2}
$$

In a semiconductor the carrier concentration denoted as (N) and also it varies according to the square of plasma frequency $\mathrm{w}_{\mathrm{p}}$ as [16-17]

$$
\mathrm{W}_{\mathrm{p}}^{2}=(4 \pi N e 2)(m e * \epsilon \propto)
$$

Using equation 12 we calculate carrier concentration and plasma frequency [18 -20] If the carrier concentration is known the effective mass of the charge carrier could be found out from the plasma frequency. The band gap energies increase due to the decrease in crystallite size.

\section{Conclusion:}

Using sol gel dip coating method the various concentration of tin doped with indium oxide powder was coated in the clean glass substrate. Structural property and its micro behaviour of prepared films were analysed by XRD techniques which indicate bixbyte structure corresponding (222) peak. From the XRD measurement data we found some microstructure property. The Grain size increases with decrease of tin concentration (5\%). Energy dispersive spectra confirm the presence of tin, indium and oxide are presented in our samples. Surface roughness observed in the atomic force microscopy. Tin concentration increases to $10 \%$ the resistivity of the films decreased from $20 \mathrm{ohm} \mathrm{cm}$ (Indium oxide at 450 $\left.{ }^{\circ} \mathrm{C}\right)$ to $0.01 \mathrm{ohm} \mathrm{cm}$.Beyond $10 \%$ tin the resistivity increases from $0.1 \mathrm{ohm} \mathrm{cm}$ to $250 \mathrm{ohm} \mathrm{am}$ at $70 \%$ tin concentration. The value of mobility and carrier concentration increases up to $10 \%$ tin concentration beyond this value of Tin oxide the carrier density decreases. Finally we have to calculate the single oscillator and dispersion energy were calculated from the data of 
optical transmission measurements in the ITO thin films. This material well suitable for solar cell application, sensors behaviour and also photo activity degradation of dye and other organic pollutants.

\section{Acknowledgement:}

The authors are thankful the Sri Sairam Engineering college management and teaching faculty for their unfailing word of encouragement and their willingness to help me. Funding project:

No

\section{References:}

1. M. J. Alam and D. C. Cameron, Thin Solid Films, 337455 (2000).

2. C. N. de Carvalho, A. M. B. do Rego, A. Amaral, P. Broguerira, G. Lavareda. Surface and coating Technology, 70-75 124 (1) (2000).

3. F. O. Adurodija, H. Ishiihara, H. Yoshioka, K. Yamada, H. Matsui et al. Thin Solid Films 338 (1-2) 13-19 (1999).

4. N. Mori, S. Ooki, N. Masubuchi, A. Tanaka, M. Kogoma, T. Ito Thin Solid Films $4116(2002)$.

5. H. R. Fallah, M. Ghasemi, A. Hassanzadeh, H. Steki, Mater.Res.Bull.42 487 (2007) .

6. J. George, and C. S. Menon, Surf.Coat.Technol.132 42 (2000).

7. G. Ramanathan, K. R. Murali International Journal of Chemtech Research 11 298307 (2018).

8. G. Frank, H. Kostlin, A. Rabenau, Phys.Stat.Solid A 52231 (1979).

9. A.EI.Hichou, A. Kachouane, J. L. Bubendorff, M. Addou, J. Ebothe, M. Troyon, A.Bougrine Thin solid films 458 (1-2) 263-268 (2004).

10. I. Hamberg, C. G. Granqvist, J.Appl.Phys.60 R123(1986).

11. H. R. Fallah, M. Ghasemi, A. Hassanzadeh, Physica E,39 69 (2007)

12. J. F. Smith, A. J. Aronson, D. Chen, W. H. Class, Thin Solid Films, 72469 (1980).

13. R. Swanepoel, J.Phys. E. Sci.instrum 17896 (1984).

14. V. Senthilkumar, P. Vickraman, M. Jeyachandran, C. Sanjeeviraja vacuum 2010.

15. J. C. Osuwa, C. I. Oriaku, I. A. Kalu, Chalcogenide Lett. 6-9 433-436 (2009).

16. V. Dhanasekaran, T. Mahalingam J.of Alloys and compound 539 50-56 (2012).

17. J. C. Manitacier, J. Casiot, P. Fillard, J.Phys. E 9 1002-1004 (1976). 
18. J. N. Zeng, J. K. Low, Z. M. Ren, T. Liaw, Y. F. Lu,Appl.Surf.Sci.197 362-367 (2002).

19. R. Swanepoel, J.Phys. E.Sci.instrum 161214 (1983)

20. V. Dhanasekaran, T. Mahalingam, R. Chandramohan, Jin Koo Rhee, j. P. Chu Thin solid films $\mathbf{5 2 0}$ 6608-6613 (2012).

21. G.Ramanathan, John Xavier, K.R.Murali IOSR Journal of Applied Physics 2(6) 47 50 (2013). 
Figures

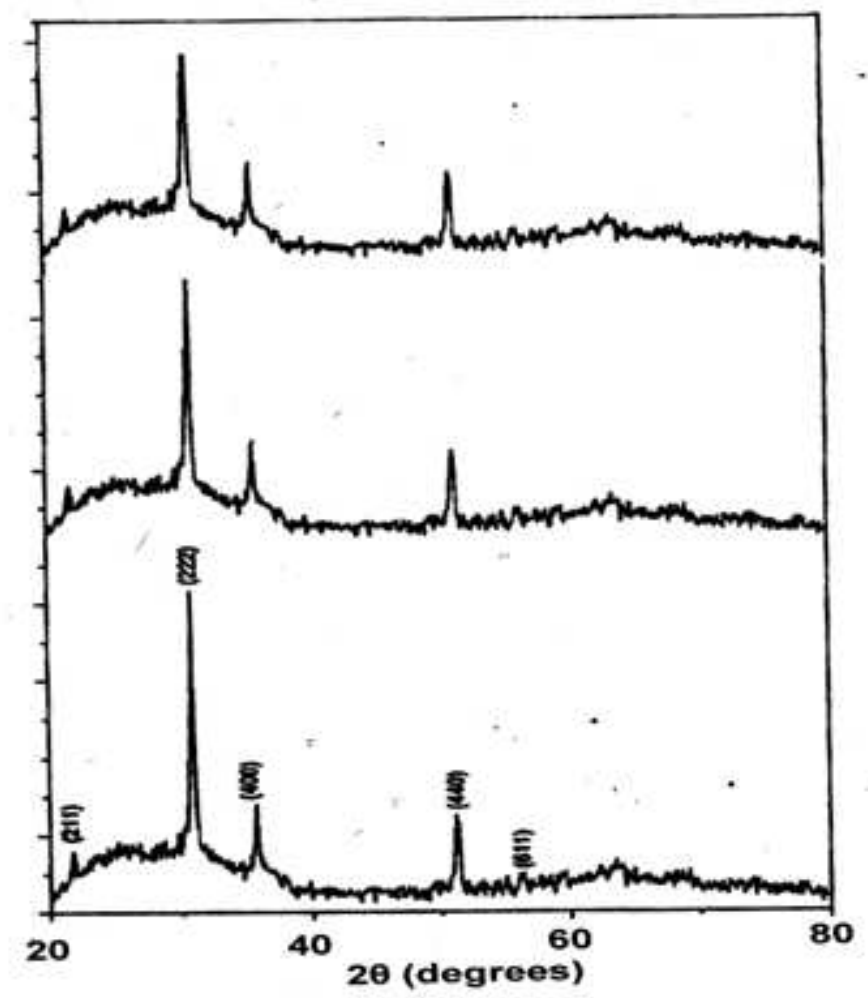

Figure 1

X-Ray diffraction pattern of $10 \%$ tin oxide in ITO films formed at different temperatures (a) $350^{\circ} \mathrm{C}$ (b) 400 ${ }^{\circ} \mathrm{C}$ (c) $450^{\circ} \mathrm{C}$

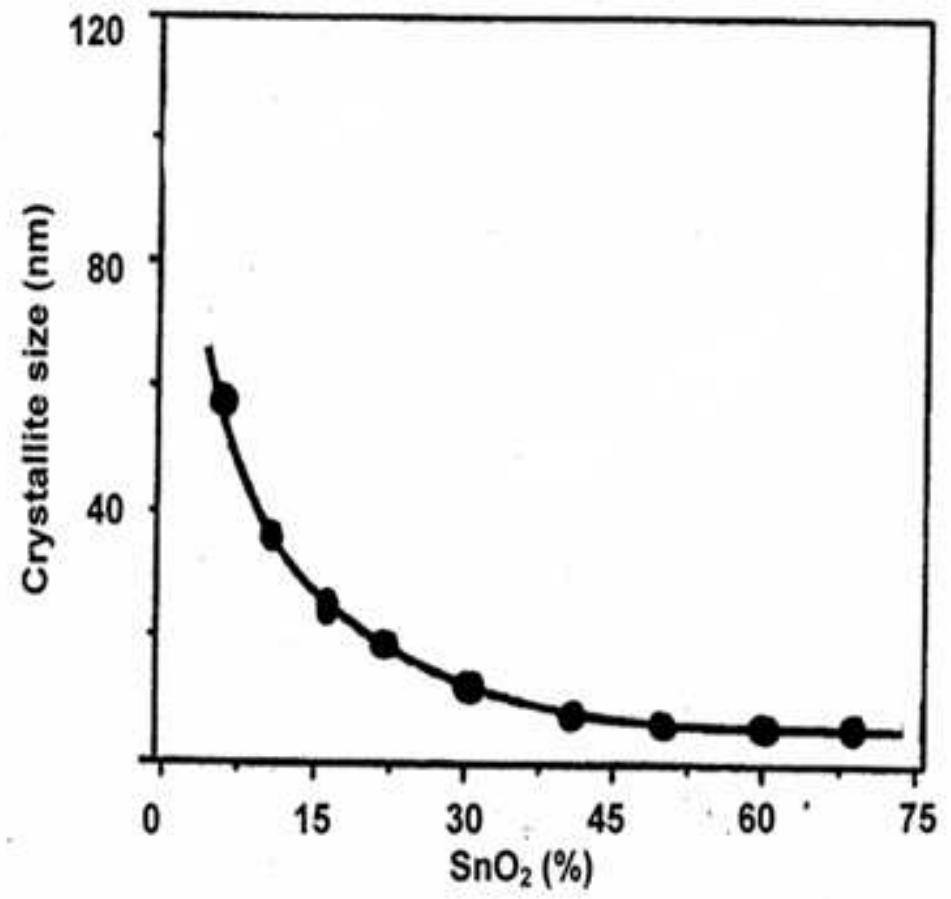


Figure 2

Mean crystallite size with increase of tin concentration.

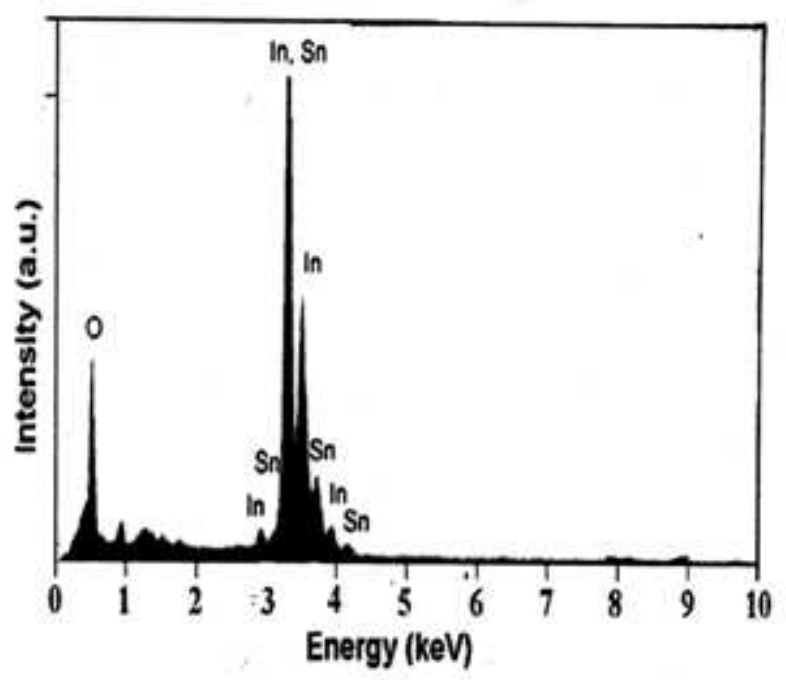

Figure 3

shows EDXA spectrum of ITO films ( $90 \%$ Indium oxide- $10 \%$ tin oxide)

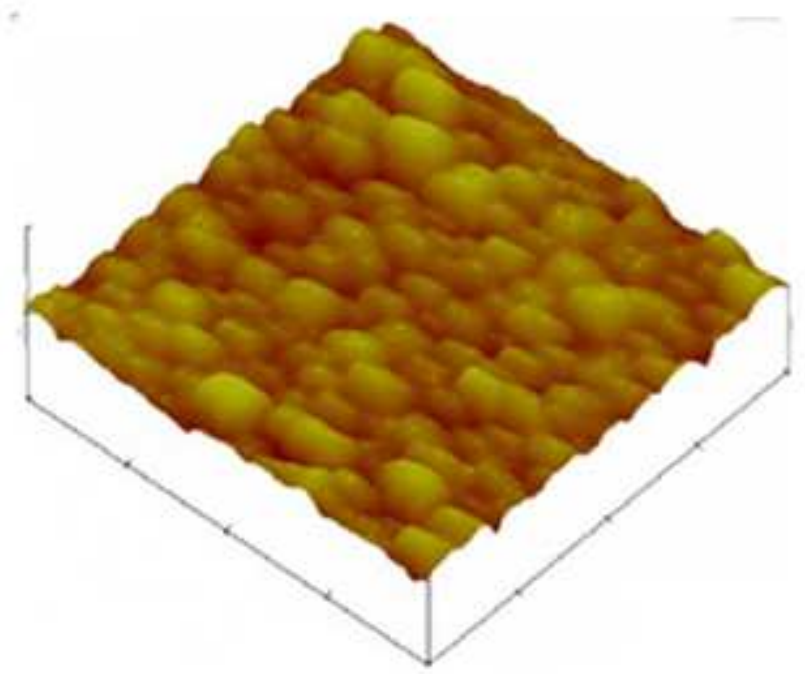

Figure 4

shows AFM of ITO films formed at $450{ }^{\circ} \mathrm{C}$ 

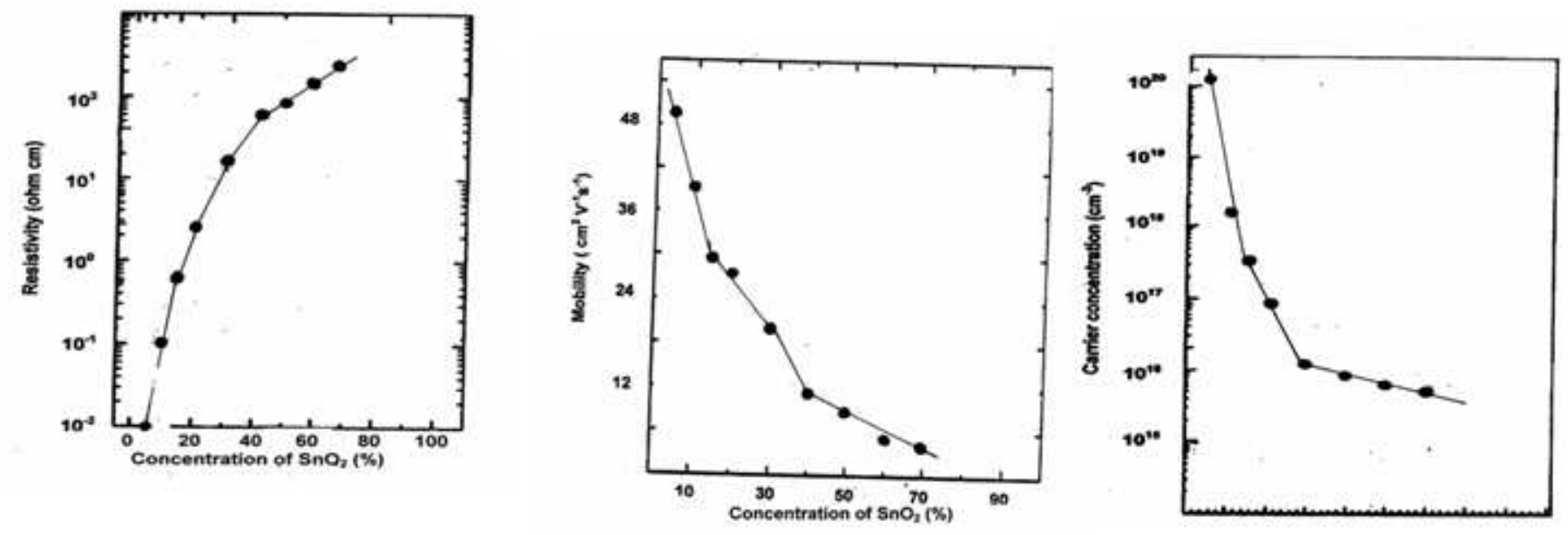

Figure 5

shows the variation of room temperature resistivity, mobility and carrier concentration of ITO films with different concentration of tin oxide
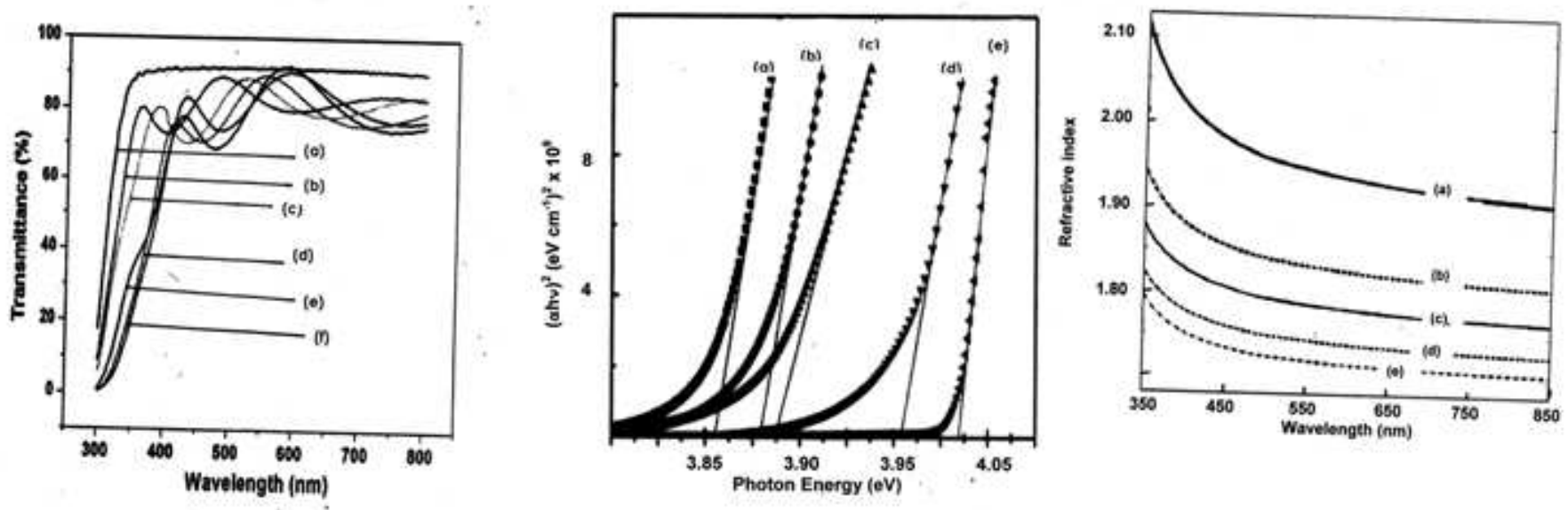

\section{a}

\section{b.}

\section{C}

Figure 6

shows the (a) Transmission spectra (b) Tauc's plot (C) Refractive index with wavelength of ITO films with different concentrations of tin oxide (a) glass (b) $70 \%$ (c) $50 \%$ (d) $30 \%$ (e) $15 \%$ (f) $5 \%$ 

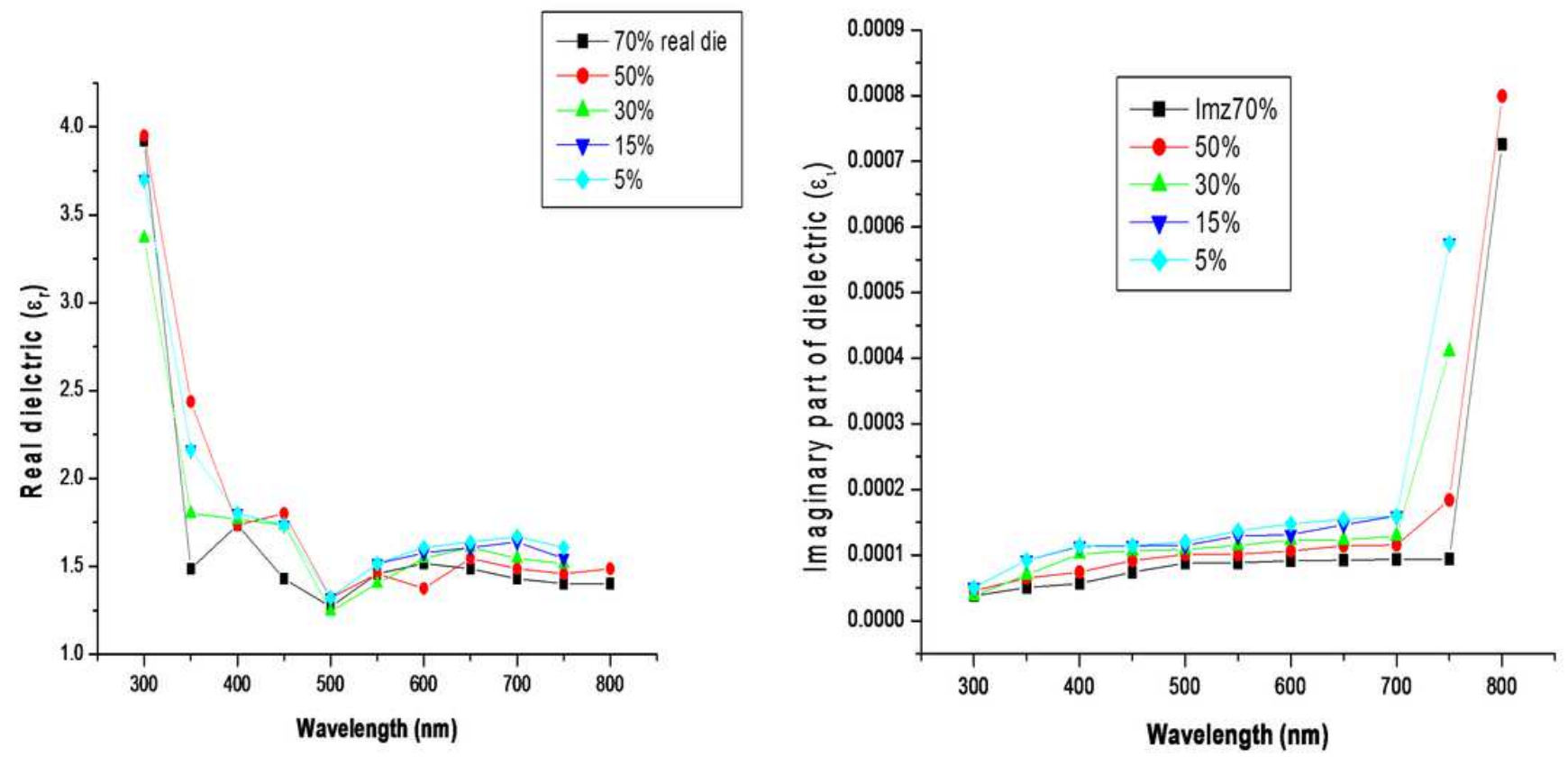

Figure 7

shows the variation of real part of dielectric and imaginary part of dielectric as a function of wavelength 

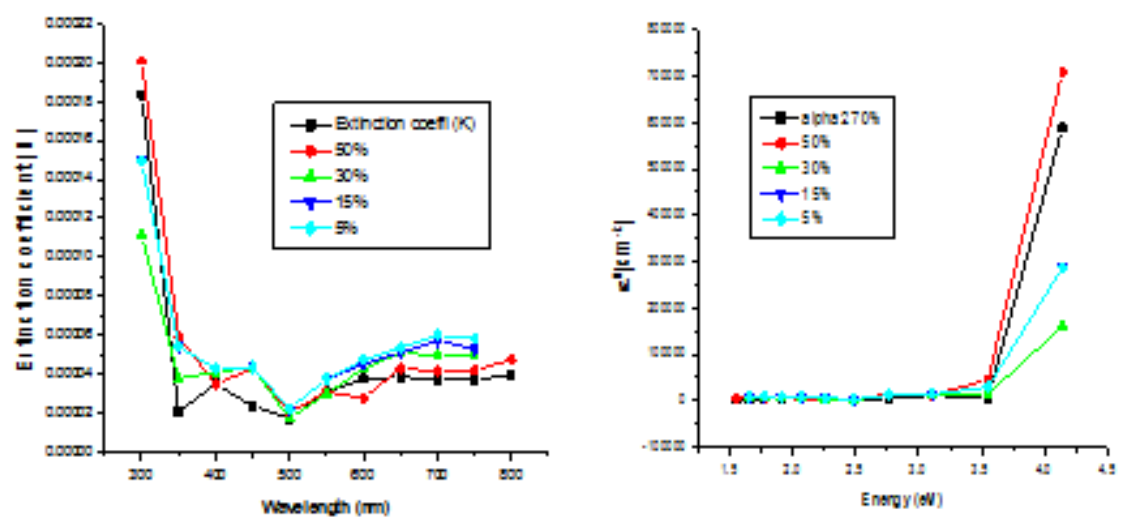

\section{Figure 8}

shows variation of extinction coefficient of ITO thin films at various compositions.
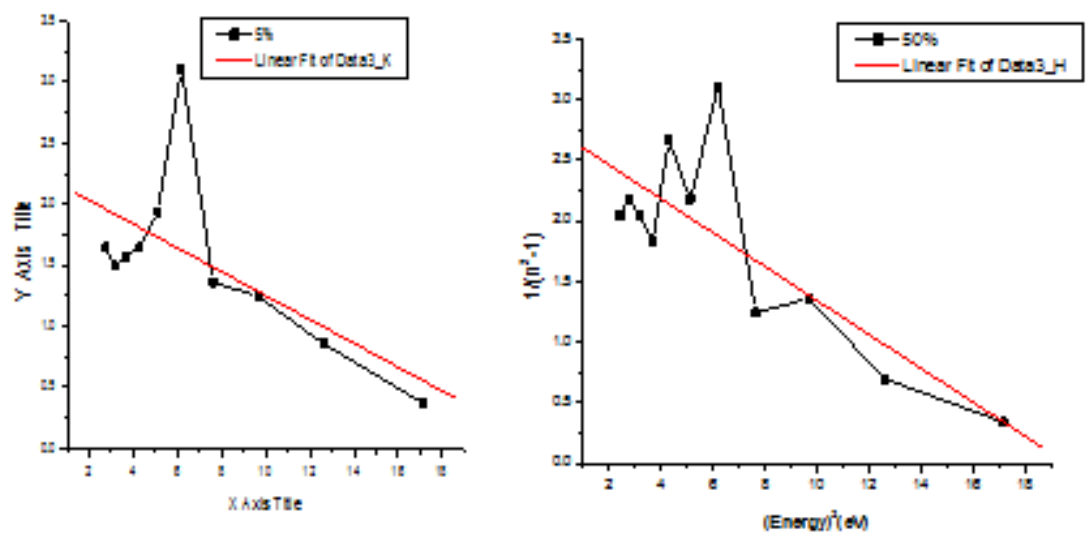

Figure 9

shows variation of (n2-1)-1 as a function of E2 for $5 \%$ and $50 \%$ tin concentration for Indium oxide thin films. 